\title{
Treatment Effects of the Herbst Appliance in Class II Malocclusion Patients after the Growth Peak
}

\author{
Rodrigo Hermont Cançado ${ }^{1,4}$ Guilherme Janson ${ }^{2}$ Bryan Tompson ${ }^{3}$ José Carlos de Castro Alvares ${ }^{4}$ \\ Fabrício Pinelli Valarelli ${ }^{4}$ Karina Maria Salvatore Freitas ${ }^{4 \odot}$
}

\footnotetext{
${ }^{1}$ Department of Restorative Dentistry, Federal University of Minas Gerais, Belo Horizonte, Brazil

${ }^{2}$ Department of Orthodontics, Bauru Dental School, University of São Paulo, Bauru, Brazil

${ }^{3}$ Department of Orthodontics, Faculty of Dentistry, University of Toronto, Toronto, Canada

${ }^{4}$ Department of Orthodontics, Uningá University Center, Maringá, Paraná, Brazil
}

Eur J Dent:2021;5:39-46

\author{
Address for correspondence Karina Freitas, DDS, MSc, PhD, \\ Department of Orthodontics, Uningá University Center, \\ Rod PR 317, 6114, Maringa - PR - 87035-510, Brazil \\ (e-mail:kmsf@uol.com.br).
}

\begin{abstract}
Keywords

- angle Class II malocclusion

- young adult

- cephalometry

- age factors

Objective The aim of this study was to evaluate dentoskeletal changes in the treatment of Class II malocclusion with the Herbst Cantilever Bite Jumper (CBJ) appliance, associated with multibracket appliances after the growth peak, at pretreatment.

Materials and Methods A sample of 37 individuals was divided into two groups: the experimental group comprised 16 patients treated consecutively for a mean period of 2.52 years with the Herbst $\mathrm{CB}$ J appliance associated with multibracket appliances. A total of 21 subjects ( 10 males and 11 females) with Class II malocclusion and mean age at T1 of 16.08 years were followed for a mean period of 2.12 years composed the control group. Comparisons between the two groups were performed using initial and final lateral cephalograms. Comparisons between experimental and control groups at pretreatment and of the treatment changes were performed by Mann-Whitney or independent $t$-tests.

Results Experimental group exhibited a significantly greater labial inclination of the mandibular incisors in comparison to the control group. Additionally, significantly greater corrections in overbite, overjet, and molar relationship were observed in the experimental than in the control groups.

Conclusion The effects of the Herbst CBJ appliance, associated with fixed appliances after the growth peak in Class II malocclusion treatment are correction in molar relationship toward a Class I relationship, decrease of the overjet, decrease of the overbite, and mandibular incisors labial inclination.
\end{abstract}

\section{Introduction}

Class II malocclusion is related to a deficient relationship between upper and lower apical bases, and may be due to dentoalveolar or skeletal components. ${ }^{1}$ This malocclusion may be related to protrusion of the maxilla, as well as of the maxillary teeth, retrusion of the mandible and/or mandibular teeth, or a combination of these factors.
Among the types of skeletal Class II malocclusion, mandibular retrusion is the most frequent in orthodontics. ${ }^{2}$ Thus, the use of functional orthopedic appliances, which redirects mandibular growth and should be used during the craniofacial growth, represents a great indication that provides good occlusion and harmony of the facial profile. $^{3-5}$
DOI https://doi.org/ 10.1055/s-0040-1715789 ISSN $1305-7456$. (c) 2020. European Journal of Dentistry.

This is an open access article published by Thieme under the terms of the Creative Commons Attribution-NonDerivative-NonCommercial-License, permitting copying and reproduction so long as the original work is given appropriate credit. Contents may not be used for commercial purposes, or adapted, remixed, transformed or built upon. (https://creativecommons.org/licenses/by-nc-nd/4.0/)

Thieme Medical and Scientific Publishers Pvt. Ltd., A-12, 2nd Floor, Sector 2, Noida-201301 UP, India 
There are several types of functional appliances; most of which are similar to each other in treatment effects. ${ }^{6,7}$ Many of these appliances are removable, which require good compliance and motivation of the patient. ${ }^{8}$ However, some studies have shown that compliance of Class II patients with removable functional appliances is deficient. ${ }^{9,10}$

In 1979, the Herbst appliance was reintroduced by Hans Pancherz ${ }^{11}$ in an attempt to minimize the problem of patient compliance since the mandibular advancement was performed by a fixed device, promoting a continuous force 24 hours a day. ${ }^{12}$

However, the treatment effects with the Herbst appliance, regarding the growth period, are still questionable. ${ }^{13,14}$ Pancherz and Hagg ${ }^{15}$ evaluated the treatment effects of 70 consecutive patients with Class II malocclusion treated with the Herbst appliance. Patients were divided into three groups according to the growth-stage at pretreatment: prepeak, peak, and postpeak. They concluded that sagittal condylar growth was most pronounced in the peak period and incisors inclination was most extensive in the postpeak period. Konik et a ${ }^{16}$ evaluated Class II patients before and after the pubertal growth peak treated with the Herbst appliance. Dentoalveolar changes represent the main differences between the late and the early treated patients. Lingual inclination of the maxillary incisors and buccal inclination of the mandibular incisors were significantly greater in the late treated group than in the early treated group. Ruf and Pancherz ${ }^{17}$ evaluated dental and skeletal changes responsible for Class II correction in young patients. They found that the amount of skeletal change contributing to overjet and molar correction was smaller in the young adult group (22 and $25 \%$, respectively) than in the early adolescent group (39 and $41 \%$, respectively). On the other hand, Chhibber et al ${ }^{18}$ found no difference in overall dentoskeletal effects in Class II patients treated with a semirigid fixed functional appliance before or after the pubertal growth spurt. Frye et al ${ }^{19}$ evaluated dentoskeletal effects in Class II patients treated with two fixed functional appliances and concluded that an increase in patient age entails more inclination of the maxillary and mandibular incisors and the growth-inhibiting effect on the maxilla is a common skeletal effect in younger patients.

Few studies to date have analyzed the treatment effects of the Herbst appliance after the growth peak, ${ }^{19-21}$ and none of these studies have compared these effects with a comparable control group. The aim of the present study is to evaluate the effects of Class II malocclusion treatment with the Herbst Cantilever Bite Jumper (CBJ) appliance, combined with multibracket appliances after the growth peak at pretreatment.

\section{Materials and Methods}

This study received approval from the Human Research Ethics Committee of Brazil (CAAE: 70881517.2.0000.5220) and Institutional Review Board of Bauru Dental School, University of São Paulo. The experimental group was retrospectively selected and initially comprised all patients with Class II malocclusion treated consecutively with the Herbst CBJ appliance, associated with 0.022-inch multibracket appliances. Sixteen patients were selected to compose the experimental group according to the following inclusion criteria: (1) no previous orthodontic treatment; (2) no tooth losses up to the permanent first molars; (3) complete orthodontic records at pretreatment (T1) and posttreatment (T2) stages; (4) patients after the growth peak at pretreatment stage (T1), as analyzed on carpal radiographs; and (5) patients were treated nonextraction of permanent teeth.

In this way, the experimental group was composed of 32 lateral cephalograms obtained at pretreatment (T1) and posttreatment (T2) stages, and 16 dental casts obtained at pretreatment stage (T1) of 16 patients ( 6 males and 10 females) presenting with Class II malocclusion. Their initial mean age was 16.37 years (standard deviation [SD] = 6.49), and their final mean age was 18.89 ( $\mathrm{SD}=6.60$ ), so the mean treatment time was 2.52 years $(S D=1.00)$. Patients presented at $\mathrm{T} 1 \mathrm{a}$ mean $\mathrm{ANB}$ angle of $6.54(\mathrm{SD}=3.08)$ degrees and a mean overjet of $6.94(\mathrm{SD}=2.24) \mathrm{mm}$. Experimental group was gathered and treated by only one orthodontist (J.C.C.A.). Considering the severity of the anteroposterior molar relationship between the maxillary and mandibular arches, four patients presented $1 / 2$ Class II, four patients $3 / 4$ Class II, and eight patients complete Class II malocclusion. To classify the patients as after the growth peak, the skeletal maturation stages of the median phalanx of the third finger was evaluated on carpal radiographs. The patients were classified after the growth peak when the radiographic interpretation comprised the stage in which the epiphysis did not present the width of the metaphysis up to the stage with complete fusion of the epiphysis and metaphysis.

The control group was obtained from the Burlington Growth Center, Toronto, Canada. This group comprised 21 subjects (10 males and 11 females) with Class II malocclusion, with no previous orthodontic treatment, with a mean age at $\mathrm{T} 1$ of 16.08 years $(\mathrm{SD}=0.10)$ and a mean age at $\mathrm{T} 2$ of 18.20 ( $\mathrm{SD}=0.28$ ), who were longitudinally followed for a mean period of 2.12 years $(S D=0.27$ ). These subjects presented at $\mathrm{T} 1 \mathrm{a}$ mean ANB angle of $3.71(\mathrm{SD}=2.04)$ degrees and a mean overjet of $4.05(\mathrm{SD}=1.76) \mathrm{mm}$.

The Herbst CBJ appliance design was described in detail in previously published article. ${ }^{20}$ After removal of the Herbst CBJ appliance, the corrected anteroposterior relationship was retained with 3/16-inch Class II elastics as active retention for a mean period of 3 months. Patients were instructed to use 3/16-inch Class II elastics for 18 hours a day, removing it only for eating, brushing, and contact sports, and patient compliance was monitored monthly. As retention, a Hawley plate was used in the upper arch and a canine to canine bonded retainer was used in the lower arch after removal of the multibracket appliances.

Lateral cephalograms obtained at T1 and T2 were analyzed. All lateral cephalograms were obtained in three different X-ray machines, and the magnification of each machine was calculated for greater accuracy. The different types of $\mathrm{X}$-ray machines produced percentages of magnification ranging from 8.2 to $11.13 \%$.

A Microtek ScanMaker i800 scanner (Microtek International, Inc.; Carson, California, United States), connected to a computer, 
was used to digitize the lateral cephalograms in a resolution of $9,600 \times 4,800 \mathrm{dpi}$. The images were transferred to the Dolphin Imaging Premium 10.5 software (Dolphin Imaging \& Management Solutions; Chatsworth, California, United States) through which the cephalometric points of interest were identified by a single investigator (R.H.C.), and angular and linear measurements were performed. The less usual cephalometric variables are illustrated in $\boldsymbol{-}$ Fig. 1.

\section{Error Study}

The same examiner (R.H.C.) repeated, after a 30-day interval, landmark identification and measurements on ten randomly selected lateral cephalograms. Random errors were

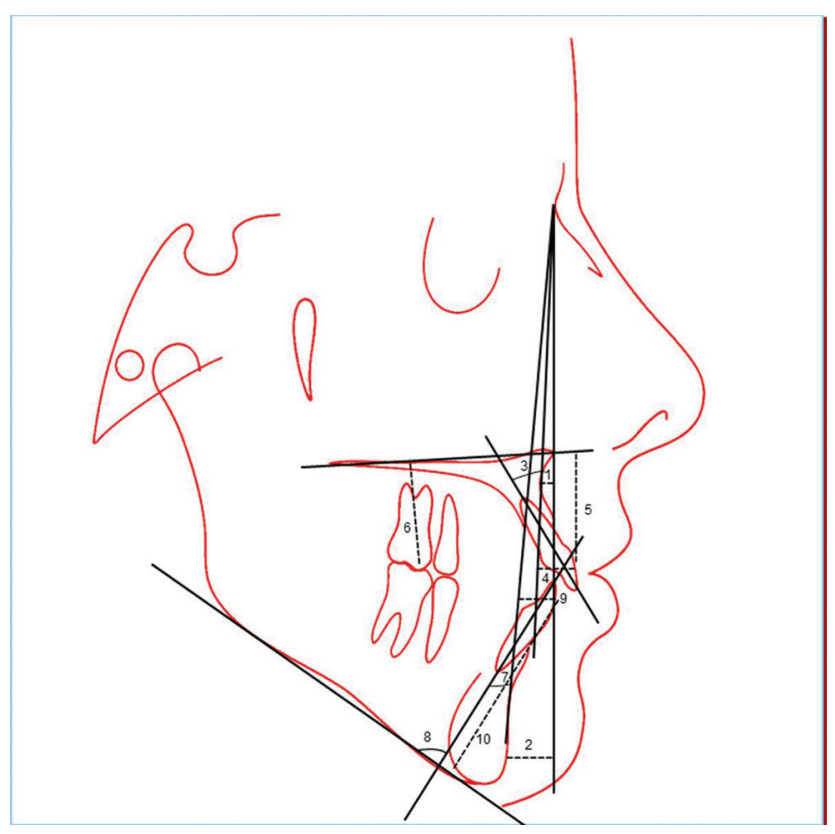

Fig. 1 Cephalometric variables: (1) A-Nperp, (2) Pog-Nperp, (3) U1.NA, (4) U1-NA, (5) U1-PP, (6) 6-PP, (7) L1.NB, (8) IMPA, (9) L1-NB, and (10) L1-MP. calculated using Dahlberg's formula. Dependent $t$-tests were used to evaluate systematic errors.

\section{Statistical Analyses}

Data distribution was evaluated using Kolmogorov-Smirnov tests. In the experimental group, SNA, SNB, and SN.Ocl at the pretreatment stage (T1) and SNA, SNB, and SN.GoGn for the treatment changes (T2-T1) did not present normal distributions. In the control group, the following cephalometric variables did not present normal distributions: 1-PP, 1-MP, and overbite for the growth changes (T2-T1). In this way, nonparametric tests were used for intergroup comparisons of these variables.

The $t$-tests were used to evaluate intergroup comparability regarding ages at $\mathrm{T} 1$ and $\mathrm{T} 2$ and the treatment/observational time. Sex and severity of Class II molar relationship distributions in the groups were evaluated with Chi-square tests.

Intergroup comparisons at pretreatment (T1) and of treatment and growth changes (T2-T1) were performed with $t$ - or Mann-Whitney U tests.

Statistical analyses were performed with Statistica software (Statistica for Windows, version 7.0, Statsoft, Inc, Tulsa, Oklahoma, United States). Results were considered statistically significant at $p<0.05$.

\section{Results}

The random errors varied from $0.42 \mathrm{~mm}$ (L1-NB) to $1.39 \mathrm{~mm}$ (Co-A), and three variables (Co-Gn, SN to Occ Plane and U6-PP) presented significant systematic errors.

The groups were comparable regarding initial and final ages, treatment/observation time and gender distribution (-Table 1).

The overjet and the initial Class II severity at $\mathrm{T} 1$ were significantly greater in the experimental than in the control group (-Table 1)

Table 1 Baseline characteristics

\begin{tabular}{|c|c|c|c|}
\hline & $\begin{array}{l}\text { Experimental group } \\
(n=16) \\
\text { Mean (SD) }\end{array}$ & $\begin{array}{l}\text { Control group } \\
(n=21) \\
\text { Mean (SD) }\end{array}$ & $p$-Value \\
\hline Initial age & $16.37(6.49)$ & $16.08(0.10)$ & $0.836^{\mathrm{b}}$ \\
\hline Final age & $18.89(6.60)$ & $18.20(0.28)$ & $0.636^{\mathrm{b}}$ \\
\hline Treatment/observation time & $2.52(1.00)$ & $2.12(0.27)$ & $0.094^{b}$ \\
\hline Overjet at T1 & $6.94(2.24)$ & $4.05(1.76)$ & $0.000^{\mathrm{a}, \mathrm{b}}$ \\
\hline $\begin{array}{l}\text { Gender } \\
\text { Male } \\
\text { Female }\end{array}$ & $\begin{array}{l}6 \\
10\end{array}$ & $\begin{array}{l}10 \\
11\end{array}$ & $\begin{array}{l}0.538^{c} \\
\text { Chi-square value }=0.37\end{array}$ \\
\hline $\begin{array}{l}\text { Molar relationship } \\
1 / 4 \text { Class II } \\
1 / 2 \text { Class II } \\
\text { Class II } \\
\text { Complete class II }\end{array}$ & $\begin{array}{l}0 \\
4 \\
4 \\
8\end{array}$ & $\begin{array}{l}2 \\
15 \\
3 \\
1\end{array}$ & $\begin{array}{l}0.004^{\mathrm{a}, \mathrm{c}} \\
\text { Chi-square value }=13.52\end{array}$ \\
\hline
\end{tabular}

Abbreviation: SD, standard deviation.

a'Statistically significant.

bIndependent $t$-test.

'Chi-square test. 
Table 2 Results of the comparison of the pretreatment (T1) cephalometric characteristics between experimental and control groups

\begin{tabular}{|c|c|c|c|c|c|}
\hline \multirow[t]{2}{*}{ Variables } & \multicolumn{2}{|c|}{$\begin{array}{l}\text { Experimental group } \\
\qquad(n=16)\end{array}$} & \multicolumn{2}{|c|}{$\begin{array}{l}\text { Control group } \\
\quad(n=21)\end{array}$} & \multirow[t]{2}{*}{$p$-Value } \\
\hline & $\begin{array}{l}\text { Mean } \\
\text { (median) }\end{array}$ & $\begin{array}{l}\text { SD } \\
(I R)\end{array}$ & $\begin{array}{l}\text { Mean } \\
\text { (median) }\end{array}$ & $\begin{array}{l}\text { SD } \\
(I R)\end{array}$ & \\
\hline \multicolumn{6}{|l|}{ Maxillary component } \\
\hline SNA (degrees) & $(83.50)$ & $(7.20)$ & $(82.10)$ & $(2.80)$ & $0.736^{\mathrm{b}}$ \\
\hline A-Nperp (mm) & -0.48 & 4.52 & -0.75 & 2.07 & $0.809^{c}$ \\
\hline Co-A (mm) & 84.76 & 3.17 & 83.07 & 4.11 & $0.182^{c}$ \\
\hline \multicolumn{6}{|c|}{ Mandibular component } \\
\hline SNB (degrees) & $(77.90)$ & $(6.50)$ & $(78.50)$ & $(4.40)$ & $0.244^{\mathrm{b}}$ \\
\hline Pog-Nperp (mm) & -11.25 & 7.26 & -4.81 & 3.54 & $0.001^{a, c}$ \\
\hline Co-Gn (mm) & 108.56 & 5.78 & 105.12 & 4.63 & $0.052^{c}$ \\
\hline \multicolumn{6}{|c|}{ Maxillomandibular relationship } \\
\hline ANB (degrees) & 6.54 & 3.08 & 3.71 & 2.04 & $0.002^{\mathrm{a}, \mathrm{c}}$ \\
\hline Wits (mm) & 1.14 & 4.79 & 1.92 & 1.93 & $0.502^{c}$ \\
\hline \multicolumn{6}{|l|}{ Growth pattern } \\
\hline FMA (degrees) & 28.32 & 6.03 & 24.08 & 4.50 & $0.019^{a, c}$ \\
\hline SN.GoGn (degrees) & 28.01 & 19.22 & 27.05 & 5.35 & $0.827^{c}$ \\
\hline $\begin{array}{l}\text { SN to Occ Plane } \\
\text { (degrees) }\end{array}$ & $(15.00)$ & $(6.90)$ & $(12.20)$ & $(6.20)$ & $0.141^{b}$ \\
\hline $\mathrm{LAFH}(\mathrm{mm})$ & 63.12 & 8.28 & 61.58 & 4.58 & $0.475^{c}$ \\
\hline \multicolumn{6}{|c|}{ Maxillary dentoalveolar component } \\
\hline U1.NA (degrees) & 21.69 & 10.87 & 17.05 & 6.51 & $0.115^{c}$ \\
\hline U1-NA (mm) & 4.62 & 4.43 & 2.48 & 2.24 & $0.063^{c}$ \\
\hline $\mathrm{U} 1-\mathrm{PP}(\mathrm{mm})$ & 27.59 & 4.97 & 22.43 & 2.20 & $0.000^{\mathrm{a}, \mathrm{c}}$ \\
\hline U6-PP (mm) & 17.75 & 3.21 & 14.70 & 1.98 & $0.001^{\mathrm{a}, \mathrm{c}}$ \\
\hline \multicolumn{6}{|c|}{ Mandibular dentoalveolar component } \\
\hline L1.NB (degrees) & 29.32 & 5.57 & 22.56 & 8.21 & $0.008^{\mathrm{a}, \mathrm{c}}$ \\
\hline IMPA (degrees) & 97.97 & 7.06 & 93.18 & 7.79 & $0.062^{\mathrm{c}}$ \\
\hline $\mathrm{L} 1-\mathrm{NB}(\mathrm{mm})$ & 6.86 & 2.50 & 3.17 & 2.43 & $0.000^{a, c}$ \\
\hline L1-MP (mm) & 39.28 & 3.54 & 30.58 & 2.82 & $0.000^{\mathrm{a}, \mathrm{c}}$ \\
\hline \multicolumn{6}{|l|}{ Dental relationship } \\
\hline Molar relationship & 1.20 & 1.39 & 0.90 & 1.44 & $0.529^{c}$ \\
\hline Overjet & 6.60 & 2.61 & 3.51 & 1.50 & $0.000^{a, c}$ \\
\hline Overbite & 3.33 & 2.05 & 2.91 & 1.73 & $0.503^{c}$ \\
\hline
\end{tabular}

Abbreviations: IR, Interquartile range; LAFH, lower anterior facial height; SD, standard deviation.

aStatistically significant.

${ }^{b}$ Mann-Whitney U test.

Independent $t$-test.

The experimental group had significantly greater mandibular retrusion, skeletal Class II relationship, vertical growth pattern, and vertical development of the maxillary incisors and molars than the control group (-Table 2 ). The mandibular incisors of the experimental group presented significantly greater protrusion, extrusion and labial inclination when compared with the control group. Overjet was significantly smaller in the control than in the experimental group.

Experimental and control groups presented similar changes regarding the maxillary and mandibular components and the maxillary teeth. Corrections in the maxillomandibular relationship and increase in LAFH were significantly greater in the experimental than the control groups (-Table 3 ). The mandibular incisors had significantly greater labial inclination and protrusion, and significantly greater corrections in overbite, overjet, and molar relationship were also observed in the experimental than in the control groups.

\section{Discussion}

\section{Group Comparability}

Both groups were very similar regarding ages at T1 and T2, treatment/observation duration, and gender distribution (-Table 1). Intergroup comparability in these variables is fundamental to compare the treatment effects in Class II 
malocclusion patients treated with a fixed functional appliance because the amount of growth favors correction of the malocclusion. This ensures that growth potential in both groups is very similar. ${ }^{22-25}$

Class II molar relationship severity and overjet were significantly greater in the experimental group. However, this should not affect the comparison because even milder Class II malocclusions tend to follow the same growth pattern of more severe Class II malocclusions. ${ }^{26,27}$ Moreover, similar previous studies in the literature have also used milder Class II malocclusion control groups. 28,29

In general, the experimental and control groups were fairly comparable cephalometrically, with only nine variables presenting statistically significant differences at baseline (-Table 2 ). The intergroup differences were primarily related to mandibular position in relation to the cranial base (Pog-Nperp), maxillomandibular relationship (ANB), growth pattern (FMA), vertical development of maxillary incisors and molars (U1-PP and U6-PP), inclination, position, and vertical development of the mandibular incisors (L1.NB, L1-NB, and L1-MP) and overjet. A possible explanation for the differences in these variables is the statistically significant greater severity of Class II malocclusion (overjet and molar relationship) of the experimental in relation to control group, as has also been reported in similar studies. ${ }^{28,29}$

The greater labial inclination and protrusion of the mandibular incisors in the experimental group was probably consequent to the significantly greater amount of complete Class II malocclusions in this group (-Tables $\mathbf{1}$ and $\mathbf{2}$ ).

\section{Intergroup Comparison}

Comparisons of the treatment and growth changes of the two groups revealed, regarding the maxillary and mandibular components, that none of the evaluated variables presented statistically significant differences ( - Table 3 ). These results agree with previous studies that also found no significant skeletal changes in Herbst therapy of Class II patients after the growth peak. ${ }^{16,17,19,30}$ The increase in mandibular effective length ( $\mathrm{Co}-\mathrm{Gn})$ observed in the experimental group was inherent to normal growth because it presents similarity to the control group. Although a limitation of the present study is that the control group has a less severe Class II malocclusion, the results obtained are important to clarify that the mechanism of Class II correction in postpubertal patients treated with fixed functional appliances are mainly dentoalveolar without skeletal effects. ${ }^{31-33}$

There was significant correction in the maxillomandibular relationship (Wits) of the experimental compared to the control group, even though the increase in Co-Gn was not significantly greater than normal growth (-Table 3 ). Since this correction was only demonstrated by the Wits appraisal, it may have been consequent to the numerically greater clockwise rotation of the occlusal plane in the experimental group. With clockwise rotation of the occlusal plane, the Class II anteroposterior discrepancy decreases. ${ }^{34,35}$ Others have also reported corrections in the maxillomandibular relationship at T2with the Herbst appliance after the growth peak at pretreatment. . $^{16,17,19,30}$

Treatment with the Herbst CBJ combined with multibracket appliances showed a significant increase in lower anterior face height, which is usually observed with Herbst appliance treatment. ${ }^{16,17,19,30}$ This effect can be attributed to the force vectors of the Herbst device that moves the jaw forward and down, and also the vertical development of the lower molars consequent to the use of Class II elastics as an active retention. ${ }^{29,36}$

The maxillary dentoalveolar component did not present significantly different changes than the control group (-Table 3). The maxillary incisors had only numerically greater palatal inclination, retrusion, and extrusion in the experimental group. Likely, palatal inclination was minimized in the experimental group by incorporation of labial crown torque in the maxillary incisors during the mechanics with fixed appliances. No significant difference between experimental and control groups was observed in the vertical changes of the upper molars. The Herbst appliance restricts maxillary molars vertical development due to the telescopic mechanism that is anchored on these teeth, ${ }^{36}$ but the fixed appliance mechanics tend to extrude them. Therefore, no difference in the intergroup changes could be detected.

Labial inclination of the mandibular incisors in the experimental was significantly greater than in the control group (-Table 3). This is one of the main effects of the Herbst appliance that has been extensively described in previous studies. ${ }^{16,19,20,37-39}$ Additionally, a nonsignificant intrusive effect can also be observed in the mandibular incisors. This effect has already been expected since most of fixed functional appliances for Class II treatment produces an intrusive vector in the mandibular incisors region. ${ }^{29}$ Nevertheless, it was not significant most likely due to the effects of the fixed appliances that were used subsequently. ${ }^{38}$

The experimental group had significantly greater correction of molar relationship toward Class I, and greater overjet and overbite decreases than the control group ( - Table 3 ). These changes occurred most likely due to the association of several greater, nonsignificant, skeletal, and dentoalveolar changes, such as the increase in mandibular length, clockwise rotation of the occlusal plane, maxillary incisors palatal inclination and retrusion, and mandibular incisors labial inclination. Although individually they were not significant, when associated they were large enough to produce changes in these three variables which are dependent on the others. In very active growing patients, most of these nonsignificant changes are usually significant. ${ }^{11,40}$ However, because the patients of the current study were evaluated after the growth peak, without much growth to be modified, the changes were not significant. ${ }^{14,19,21}$ Other studies have already demonstrated similar results using the Herbst appliance. . $^{21,41,42}$

When comparing the results of the present study with other functional appliances evaluated in the same age period, it seems that treatment effects do not depend on the type of fixed functional appliance used. Kinzinger et $\mathrm{al}^{6}$ found that most of the overjet and molar relationship correction were 
Table 3 Intergroup comparison of treatment and growth changes (T2-T1)

\begin{tabular}{|c|c|c|c|c|c|}
\hline \multirow[t]{2}{*}{ Variables } & \multicolumn{2}{|c|}{$\begin{array}{l}\text { Experimental group } \\
\qquad(n=16)\end{array}$} & \multicolumn{2}{|c|}{$\begin{array}{l}\text { Control group } \\
\quad(n=21)\end{array}$} & \multirow[t]{2}{*}{$p$-Value } \\
\hline & $\begin{array}{l}\text { Mean } \\
\text { (Median) }\end{array}$ & $\begin{array}{l}\text { SD } \\
(I R)\end{array}$ & $\begin{array}{l}\text { Mean } \\
\text { (Median) }\end{array}$ & $\begin{array}{l}\text { SD } \\
\text { (IR) }\end{array}$ & \\
\hline \multicolumn{6}{|c|}{ Maxillary component } \\
\hline SNA (degrees) & $(-0.10)$ & $(4.35)$ & $(-0.40)$ & $(2.00)$ & $0.399^{b}$ \\
\hline A-Nperp (mm) & -0.28 & 3.21 & -0.25 & 2.17 & $0.975^{c}$ \\
\hline Co-A (mm) & 0.95 & 2.67 & 0.89 & 0.75 & $0.923^{c}$ \\
\hline \multicolumn{6}{|c|}{ Mandibular component } \\
\hline SNB (degrees) & $(1.25)$ & $(3.20)$ & $(-0.20)$ & $(2.20)$ & $0.086^{b}$ \\
\hline Pog-Nperp (mm) & 1.16 & 4.88 & 0.02 & 3.77 & $0.428^{c}$ \\
\hline Co-Gn (mm) & 3.72 & 3.11 & 2.31 & 1.07 & $0.060^{c}$ \\
\hline \multicolumn{6}{|c|}{ Maxillomandibular relationship } \\
\hline ANB (degrees) & -1.11 & 2.79 & -0.25 & 1.31 & $0.224^{c}$ \\
\hline Wits (mm) & -2.61 & 5.64 & 0.17 & 1.63 & $0.039^{\mathrm{a}, \mathrm{c}}$ \\
\hline \multicolumn{6}{|l|}{ Growth pattern } \\
\hline FMA (degrees) & -0.02 & 2.49 & -0.13 & 3.09 & $0.908^{c}$ \\
\hline SN.GoGn (degrees) & $(-0.65)$ & $(4.30)$ & $(0.50)$ & $(3.60)$ & $0.988^{b}$ \\
\hline $\begin{array}{l}\text { SN to Occ Plane } \\
\text { (degrees) }\end{array}$ & 7.39 & 17.86 & -0.01 & 2.68 & $0.068^{c}$ \\
\hline LAFH (mm) & 2.28 & 1.91 & 0.79 & 1.03 & $0.004^{\mathrm{a}, \mathrm{c}}$ \\
\hline \multicolumn{6}{|c|}{ Maxillary dentoalveolar component } \\
\hline U1.NA (degrees) & -2.38 & 8.81 & 0.35 & 2.44 & $0.184^{c}$ \\
\hline U1-NA (mm) & -1.23 & 4.12 & 0.38 & 1.19 & $0.096^{c}$ \\
\hline U1-PP (mm) & $(1.10)$ & $(2.15)$ & $(0.10)$ & $(1.00)$ & $0.177^{b}$ \\
\hline U6-PP (mm) & 0.68 & 1.78 & 1.16 & 1.93 & $0.444^{c}$ \\
\hline \multicolumn{6}{|c|}{ Mandibular dentoalveolar component } \\
\hline L1.NB (degrees) & 3.47 & 4.32 & -0.68 & 2.67 & $0.001^{\mathrm{a}, \mathrm{c}}$ \\
\hline IMPA (degrees) & 2.65 & 4.58 & -0.13 & 2.60 & $0.025^{\mathrm{a}, \mathrm{c}}$ \\
\hline $\mathrm{L} 1-\mathrm{NB}(\mathrm{mm})$ & 0.79 & 1.17 & 0.08 & 0.98 & $0.051^{c}$ \\
\hline L1-MP (mm) & $(-0.30)$ & $(2.95)$ & $(0.40)$ & $(1.00)$ & $0.114^{b}$ \\
\hline \multicolumn{6}{|l|}{ Dental relationship } \\
\hline Molar relationship & -2.28 & 2.15 & -0.56 & 1.53 & $0.007^{\mathrm{a}, \mathrm{c}}$ \\
\hline Overjet & -3.36 & 2.87 & -0.01 & 1.05 & $0.000^{a, c}$ \\
\hline Overbite & $(-2.25)$ & $(1.70)$ & $(0.20)$ & $(0.90)$ & $0.000^{\mathrm{a}, \mathrm{b}}$ \\
\hline
\end{tabular}

Abbreviations: IR, Interquartile range; LAFH, lower anterior facial height; SD, standard deviation.

aStatistically significant.

bMann-Whitney U test.

Independent $t$-test.

primarily due to significant dentoalveolar changes when evaluating treatment of 21 patients with Class II malocclusion treated with the Functional Mandibular Advancer appliance. Another study conducted by Nalbantgil et a $\mathrm{l}^{33}$ concluded that Jasper Jumper treatment, in conjunction with multibracket appliance, during the postpubertal growth spurt corrects Class II discrepancies mostly through dentoalveolar changes. Ghislanzoni et al $^{31}$ reported significant dentoalveolar compensations in the mandibular arch such as proclination of incisors, extrusion, and mesialization of molars in the postpubertal group treated with the mandibular advancement repositioning appliance appliance. Oztoprak et a $\mathrm{l}^{32}$ compared
Class II treatment effects using Sabbagh Universal Spring and Forsus appliances during the postpubertal growth spurt and concluded that correction of Class II anteroposterior discrepancies were achieved through dentoalveolar changes.

\section{Conclusion}

The effects of the Herbst CBJ appliance associated with fixed appliances after the growth peak in Class II malocclusion treatment are correction in molar relationship toward a Class I relationship, correction of the overjet, correction of the overbite, and mandibular incisors' labial inclination. 


\section{Conflict of Interest}

None declared.

\section{References}

1 Sassouni V. A classification of skeletal facial types. Am J Orthod 1969;55(2):109-123

2 McNamara JA Jr. Components of class II malocclusion in children 8-10 years of age. Angle Orthod 1981;51(3):177-202

3 Martina S, Di Stefano ML, Paduano FP, Aiello D, Valletta R, Paduano S, Evaluation of profile changes in class II individuals treated by means of herbst miniscope appliance. Dent J (Basel)2020;8(1):27

4 Moresca AHK, de Moraes ND, Topolski F, et al. Esthetic perception of facial profile changes in Class II patients treated with Herbst or Forsus appliances [published online ahead of print, 2020 Feb 24]. Angle Orthod 2020;10.2319/052719-362.1 doi:10.2319/052719-362.1

5 Celikoglu M, Unal T, Bayram M, Candirli C. Treatment of a skeletal class II malocclusion using fixed functional appliance with miniplate anchorage. Eur J Dent 2014;8(2):276-280

6 Kinzinger GSM, Lisson JA, Frye L, Gross U, Hourfar J. A retrospective cephalometric investigation of two fixed functional orthodontic appliances in class II treatment: functional mandibular advancer vs. herbst appliance. Clin Oral Investig 2018;22(1):293-304

7 Zymperdikas VF, Koretsi V, Papageorgiou SN, Papadopoulos MA. Treatment effects of fixed functional appliances in patients with class II malocclusion: A systematic review and meta-analysis. Eur J Orthod 2016;38(2):113-126

8 Portelli M, Militi A, Cicciù M, et al. No compliance correction of class II malocclusion in growing patients Whit HERBST appliance: a case report. Open Dent J 2018;12:605-613

9 Sahm G, Bartsch A, Witt E. Micro-electronic monitoring of functional appliance wear. Eur J Orthod 1990;12(3):297-301

10 Sahm G, Bartsch A, Witt E. Reliability of patient reports on compliance. Eur J Orthod 1990;12(4):438-446

11 Pancherz $\mathrm{H}$. Treatment of class II malocclusions by jumping the bite with the Herbst appliance: a cephalometric investigation. Am J Orthod 1979;76(4):423-442

12 Bock N, Ruehl J, Ruf S. Orthodontic class II:1 treatment-efficiency and outcome quality of Herbst-multibracket appliance therapy. Clin Oral Investig 2018;22(5):2005-2011

13 Fan Y, Schneider P, Matthews H, et al. 3D assessment of mandibular skeletal effects produced by the Herbst appliance. BMC Oral Health 2020;20(1):117

14 Perinetti G, Primožič J, Furlani G, Franchi L, Contardo L. Treatment effects of fixed functional appliances alone or in combination with multibracket appliances: A systematic review and meta-analysis. Angle Orthod 2015;85(3):480-492

15 Pancherz $H$, Hägg U. Dentofacial orthopedics in relation to somatic maturation: an analysis of 70 consecutive cases treated with the Herbst appliance. Am J Orthod 1985;88(4):273-287

16 Konik M, Pancherz H, Hansen K. The mechanism of class II correction in late Herbst treatment. Am J Orthod Dentofacial Orthop 1997;112(1):87-91

17 Ruf S, Pancherz H. Dentoskeletal effects and facial profile changes in young adults treated with the Herbst appliance. Angle Orthod 1999;69(3):239-246

18 Chhibber A, Upadhyay M, Uribe F, Nanda R. Mechanism of Class II correction in prepubertal and postpubertal patients with twin force bite corrector. Angle Orthod 2013;83(4):718-727

19 Frye L, Diedrich PR, Kinzinger GS. Class II treatment with fixed functional orthodontic appliances before and after the pubertal growth peak: a cephalometric study to evaluate differential therapeutic effects. J Orofac Orthop 2009;70(6):511-527

20 Alvares JC, Cançado RH, Valarelli FP, de Freitas KM, Angheben CZ. Class II malocclusion treatment with the Herbst appliance in patients after the growth peak. Dental Press J Orthod 2013;18(5):38-45

21 Ruf S, Pancherz H. Herbst/multibracket appliance treatment of Class II division 1 malocclusions in early and late adulthood. A prospective cephalometric study of consecutively treated subjects. Eur J Orthod 2006;28(4):352-360

22 Buschang PH, Martins J. Childhood and adolescent changes of skeletal relationships. Angle Orthod 1998;68(3):199-206, discussion 207-208

23 Dyer GS, Harris EF, Vaden JL. Age effects on orthodontic treatment: adolescents contrasted with adults. Am J Orthod Dentofacial Orthop 1991;100(6):523-530

24 Harris EF, Dyer GS, Vaden JL. Age effects on orthodontic treatment: skeletodental assessments from the Johnston analysis. Am J Orthod Dentofacial Orthop 1991;100(6):531-536

25 Vaden JL, Harris EF, Behrents RG. Adult versus adolescent Class II correction: a comparison. Am J Orthod Dentofacial Orthop 1995;107(6):651-661

26 Janson G, Janson M, Nakamura A. de Freitas MR, Henriques JF, Pinzan A. Influence of cephalometric characteristics on the occlusal success rate of Class II malocclusions treated with 2and 4-premolar extraction protocols. Am J Orthod Dentofacial Orthop 2008;133(6):861-868

27 Janson G, Simão TM, Barros SE, Janson M, de Freitas MR. Influence of the cephalometric characteristics on the occlusal success rate of Class II malocclusions treated with nonextraction or with two maxillary premolar extraction protocols. World J Orthod 2010;11(4):e63-e71

28 Lima KJ, Henriques JF, Janson G, Pereira SC, Neves LS, Cançado RH. Dentoskeletal changes induced by the Jasper jumper and the activator-headgear combination appliances followed by fixed orthodontic treatment. Am J Orthod Dentofacial Orthop 2013;143(5):684-694

29 Neves LS, Janson G, Cançado RH, de Lima KJ, Fernandes TM, Henriques JF. Treatment effects of the Jasper Jumper and the Bionator associated with fixed appliances. Prog Orthod 2014;15:54

30 Pancherz H. The Herbst appliance-its biologic effects and clinical use. Am J Orthod 1985;87(1):1-20

31 Ghislanzoni LT, Baccetti T, Toll D. Defraia E, McNamara JA Jr, Franchi L. Treatment timing of MARA and fixed appliance therapy of Class II malocclusion. Eur J Orthod 2013;35(3):394-400

32 Oztoprak MO, Nalbantgil D, Uyanlar A, Arun T. A cephalometric comparative study of class II correction with Sabbagh Universal Spring (SUS(2)) and Forsus FRD appliances. Eur J Dent 2012;6(3):302-310

33 Nalbantgil D, Arun T, Sayinsu K, Fulya I. Skeletal, dental and soft-tissue changes induced by the Jasper Jumper appliance in late adolescence. Angle Orthod 2005;75(3):426-436

34 Jacobson A. Application of the "wits" appraisal. Am J Orthod 1976;70(2):179-189

35 Martina R, Bucci E, Gagliardi M, Laino A. [Relation between the value of the Wits Appraisal and the inclination of the occlusal plane]. Minerva Stomatol 1982;31(3):385-389

36 Langford NM Jr. The Herbst appliance. J Clin Orthod 1981;15(8):558-561

37 Jakobsone G, Latkauskiene D, McNamara JA Jr. Mechanisms of Class II correction induced by the crown Herbst appliance as a single-phase Class II therapy: 1 year follow-up. Prog Orthod 2013;14:27

38 Martin J, Pancherz H. Mandibular incisor position changes in relation to amount of bite jumping during Herbst/multibracket appliance treatment: a radiographic-cephalometric study. Am J Orthod Dentofacial Orthop 2009;136(1):44-51 
39 Pancherz H, Bjerklin K. Mandibular incisor inclination, tooth irregularity, and gingival recessions after Herbst therapy: a 32-year follow-up study. Am J Orthod Dentofacial Orthop 2014;146(3):310-318

40 Pancherz $\mathrm{H}$. The mechanism of Class II correction in Herbst appliance treatment: A cephalometric investigation. Am J Orthod 1982;82(2):104-113
41 VanLaecken R, Martin CA, Dischinger T, Razmus T, Ngan P. Treatment effects of the edgewise Herbst appliance: A cephalometric and tomographic investigation. Am J Orthod Dentofacial Orthop 2006;130(5):582-593

42 Yang $\mathrm{X}$, Zhu Y, Long $\mathrm{H}$, et al. The effectiveness of the Herbst appliance for patients with Class II malocclusion: A meta-analysis. Eur J Orthod 2016;38(3):324-333 